University of Rhode Island

DigitalCommons@URI

Civil \& Environmental Engineering Faculty

Publications

Civil \& Environmental Engineering

2017

\title{
Improving moisture sensitivity and mechanical properties of sulfur extended asphalt mixture by nano-antistripping agent
}

\author{
Masoud Faramarzi \\ University of Rhode Island \\ Behnam Golestani \\ Kang-Won Wayne Lee \\ University of Rhode Island, leekw@uri.edu
}

Follow this and additional works at: https://digitalcommons.uri.edu/cve_facpubs

The University of Rhode Island Faculty have made this article openly available.

Please let us know how Open Access to this research benefits you.

This is a pre-publication author manuscript of the final, published article.

Terms of Use

This article is made available under the terms and conditions applicable towards Open Access

Policy Articles, as set forth in our Terms of Use.

\section{Citation/Publisher Attribution}

Faramarzi, M., Golestani, B., \& Lee, K. W. (2017). Improving moisture sensitivity and mechanical properties of sulfur extended asphalt mixture by nano-antistripping agent. Construction and Building Materials, 133, 534-542. doi: 10.1016/j.conbuildmat.2016.12.038

Available at: http://dx.doi.org/10.1016/j.conbuildmat.2016.12.038

This Article is brought to you for free and open access by the Civil \& Environmental Engineering at DigitalCommons@URI. It has been accepted for inclusion in Civil \& Environmental Engineering Faculty Publications by an authorized administrator of DigitalCommons@URI. For more information, please contact digitalcommonsgroup@uri.edu. 


\title{
Improving moisture sensitivety and mechanical properties of Sulfur
}

\section{Extended Asphalt mixture by Nano- Antistripping Agent}

\author{
M. Faramarzi ${ }^{1}$, B. Golestani ${ }^{2}$, K. Wayne Lee $^{3}$ \\ ${ }^{1}$ M.Sc. Dept. of Civil Engineering, University of Guilan, Rasht, I. R. Iran \\ ${ }^{2} \mathrm{Ph} . \mathrm{D}$, Dept. of Civil, Environmental and Construction Engineering, University of Central Florida, \\ Orlando, FL, USA \\ ${ }^{3}$ Ph.D, PE, F. ASCE, Dept. of Civil and Environmental Engineering, University of Rhode Island \\ Kingston, RI 02881, USA \\ 1 faramarzi@msc.guilan.ac.ir \\ ²b.golestani@knights.ucf.edu \\ 3leekw@uri.edu
}

\begin{abstract}
Moisture damage and fatigue cracking are the most common defects of Sulfur Extended Asphalts (SEAs). Moisture damage in asphaltic mixtures occurs due to the weak cohesion and adhesion that cause the creation of different forms of pavement defects. Various methods have been implemented in order to enhance the asphalt mixture's resistance to the moisture damage. One of the main methods is the addition of anti- striping agents (ASAs) which reinforce the bonding between asphalt binder and aggregates. In this study, a series of laboratory testing has been performed to appraise the mechanical properties and moisture sensitivity of the SEA mixtures modified with ASA. In addition, Googas as a new generation of modified-sulfur-mix additive and ASA (nanotechnology Zycotherm) were employed to make warm-mix asphalt (WMA) specimens, through modification of neat asphalt (PG 64-22). Furthermore, four types of mixtures with different additives, containing ASA and sulfur, were prepared, and the moisture susceptibility, resilient modulus, rutting resistance, and fatigue behavior were measured. Obtained results, demonstrated the improvement of mechanical characteristics due to the sulfur modification, exclusively for rutting phenomenon. Moreover, nanotechnology Zycotherm (NZ) as an ASA enhanced the adhesion between aggregates and sulfur-extended asphalt; thus, the resistance of SEAs against moisture damage and fatigue cracking improved.
\end{abstract}

Keywords: WMA; Sulfur; Antistripping agent; Moisture susceptibility; Mechanical properties

\section{Introduction}

${ }^{*}$ Corresponding author.

E-mail addresses: b.golestani@knights.ucf.edu (B. Golestani) 
Asphalt is a visco-elastic binder that experiences elastic behavior during rapid loading or at low environmental temperatures and viscous behavior during slow loading or at high temperatures. This temperature- dependent behavior causes a desire to improve the properties of asphalt to resist more against the rutting phenomenon, which usually appears at high temperatures, and against cracking phenomenon, which mostly happens at low temperatures [1]. On the other hand, temperature variations between warm and cold months, as well as, increased traffic volume of trucks, create critical pressures in the structure of pavements. Such conditions have caused an increased desire to improve asphalt properties. There are various methods to modify the asphalt properties [2]. One of the most popular and common procedure is using of modifier additives such as sulfur.

Since four decades ago, many studies have demonstrated that sulfur can modify and improve the properties of asphaltic pavements [3]. Application of sulfur as an asphalt binder performance extender is an economical solution to decrease virgin binder usage as well as toxic gas emission. In spite of implementation problems, it was observed that Sulfur Extended Asphalts (SEAs) could improve pavement's mechanical properties such as stiffness compared to conventional asphalt mixtures [4]. The use of sulfur to improve the quality of asphalt began in 1970 and was commercially used during the 1970s and 1980s. Without appropriate technology at the time, handling and safety issues also were of concern, as molten sulfur was difficult to apply and occasionally generated $\mathrm{H}_{2} \mathrm{~S}$ which had prevented its application during those years. Therefore, there was an interruption period by using sulfur as an asphalt modifier in the 1980s [5], but eventually, the concept of sulfur extended asphalt (SEA) reappeared with the emersion of a new version of solid dust-free sulfur pellets. Solid dust-free sulfur facilitates the displacing of sulfur in a solid pellet shape. This new product was improved by using polymeric compounds in the sulfur pellets. By this change, it became possible to add new product to the asphaltic mixtures while emission of hazardous gasses like 
$\mathrm{H}_{2} \mathrm{~S}$ and annoying odors reduced considerably compared to the conventional-liquid sulfur extended asphaltic mixture [6]. This new product reduced mixing temperature to about $135^{\circ} \mathrm{C}$ while compaction temperature is reduced to about $90^{\circ} \mathrm{C}$. Many of the mentioned safety problems seemed to be disappeared, if the asphalt concrete was constructed at a mixing temperature of $135 \pm 5^{\circ} \mathrm{C}$. Moreover, the new sulfur pellets could be poured directly into the asphalt-aggregates mixture during the mixing operation [6]. As a result, there was no concern about difficulties of blending it with asphalt before adding the binder to the aggregates. Since mixing operation should be done in the temperature range lower than conventional HMA, it should be considered as a Warm Mix Asphalt. Mixing temperature of WMA is approximately $16-55^{\circ} \mathrm{C}$ lower than conventional HMA, therefore, using the new sulfur extended asphalt as WMA can reduce required energy to produce and compact asphalt mixture [7].

The bonding between asphalt and aggregates is considerably important as it affects the integrity of asphaltic pavement. Such bonding forms at the beginning of the mixing process when asphalt coats aggregates and this bonding should resist against stresses during its lifetime in the asphaltic pavement, while, insufficient adhesion leads to a low performance of the pavement. Divito et al. [8] showed that pavement strength depends on: (1) the asphalt's cohesive resistance, (2) the resistance of adhesive bond between the asphalt and the surface of aggregate, and (3) the interlock between the aggregates particles. ASAs are substances designed to improve chemically the adhesion between the asphaltic binder and the aggregates. They are available in both liquid and solid forms. One of the most common ASAs which has been extensively used to improve the HMA's resistance against moisture damages is hydrated lime. Other common conventional ASAs are fly-ash and Portland cement. In addition, Liquid ASAs in the form of cationic surface-active agents (principally amines) have become popular in recent years [9]. In this study, a liquid ASA commercially named 
82 Zycotherm was used to make the aggregates hydrophobic while providing improved bonding with the sulfur- extended asphalt binder.

\subsection{Literature review}

Bencovitz and Boe [10] demonstrated that sulfur could be mixed with asphalt as an extender and make asphalt cement which can modify the asphalt rheological characteristics. For the first time, Sulfur-Extended Asphalt was constructed by Kennepohl et al. [11] and practically applied in asphaltic pavements in the early 1980s as a asphalt extender to decrease asphalt consumption. Some case studies by Beatty et al. [12] showed that SEA has better function in comparison with conventional HMA.

In recent studies performed on SEAs by Strickland et al. [13] and Timm et al. [14], sulfur was applied in the form of a solid pellet which could be melted at a temperature round $120^{\circ} \mathrm{C}$ and added as asphalt extender with the ratio between $30 \%$ and $40 \%$. These pellets were pretreated to decrease toxic gas emissions like hydrogen sulfide and also to lower the temperature of mixing and compaction operations. At mixing operation, some of the sulfur homogenizes with the asphalt at $120^{\circ} \mathrm{C}$ and decreases its viscosity. The remnant crystallized and covered aggregates as the temperature is reduced. They showed that dissolved, and crystallized sulfur makes the mixture stiffer and leads to a more resistant asphalt mixture at high temperatures, and consequently less vulnerable to permanent deformation phenomenon. SEA also advantaged the sulfur as asphalt extender and decreased asphalt consumption about $20-25 \%$ of the binder weight [15]. Strickland et al. [16] suggested keeping the volume ratio of the total binder phase (asphalt and sulfur) constant at asphaltic mixture before sulfur extending and after that. This was recommended since the density of sulfur pellets is different from the base asphalt. They established a relationship between asphalt and sulfur content in the SEA based on the following Equation: 
Sulfur + asphalt $\%=\frac{100 A R}{100 R-P_{S}\left(R-G_{\text {bitumen }}\right)}$

107

In which:

Sulfur + asphalt $\%=$ sulfur- extended binder content by the weight of WMA sample; $\mathrm{A}=$ asphalt content by the weight of conventional HMA sample $(\%) ; \mathrm{R}=$ specific weight ratio (sulfur to asphalt); Ps = sulfur content in extended binder; and $G_{\text {bitumen }}=$ specific weight of the asphalt.

Strickland et al. [16] did an experimental investigation on the functional properties of SEA in the laboratory. Results indicated deteriorated tensile-strength ratio (TSR) but improved dynamic modulus in various ranges of temperature and frequency. According to the results obtained by life cycle costs analysis of SEA pavement structures conducted by Cooper et al. [17] Using SEA amplified the predicted rutting and fatigue resistance and the overall pavement service lives compare to unmodified HMA at various traffic intensities. It was also shown that SEA has the potential to reduce construction and maintenance costs in comparison with a conventional HMA produced with the same binder grade. In a study conducted by Timm et al. [14], dynamic moduli and moisture susceptibility of SEA were evaluated. Results indicated that SEA was more vulnerable against moist condition as had lower TSR in comparison with conventional asphalt mixture: however, the SEA dynamic modulus increased.

\subsection{Research Objective}

Mechanical properties and moisture sensitivity of anti-stripping agent-modified SEA were evaluated in this paper by the experimental method. Nano-based anti-stripping agent named commercially zycotherm and petroleum base sulfur named commercially Googas were used respectively to replace a portion of asphalt and strengthen the bond between the binder (sulfur and asphalt) and aggregate's surface. In this study, moisture sensitivity test, rutting performance, resilient modulus and fatigue behavior were evaluated for the proposed 
samples. Asphalt mixture tests were carried out on four different mixtures including one conventional HMA and three modified WMA (in different combinations of Sulfur and ASA additives).

\section{Test materials and mixing}

\subsection{Materials}

\subsubsection{Asphalt binder and aggregates}

Materials used in this experimental investigation included a PG 64-22 virgin asphalt binder, with the physical properties that are shown in Table 1. Used aggregates have desired mechanical properties such as enough strength, toughness and hardness. Also, crushed aggregates were used to make higher stability. The Superpave mix design [18] was used to prepare the asphalt mixtures and filler material (grinded limestone) were used to meet the aggregate gradation criteria shown in Fig. 1.

\section{Table 1}

145 Physical properties of used asphalt binder

\begin{tabular}{ccccccccc}
\hline Properties & $\begin{array}{c}\text { PG } \\
\text { grade }\end{array}$ & $\begin{array}{c}\text { Purity } \\
\text { grade }\end{array}$ & $\begin{array}{c}\text { Flash } \\
\text { point }\end{array}$ & $\begin{array}{c}\text { Softening } \\
\text { point }\end{array}$ & $\begin{array}{c}\text { Penetration } \\
\text { Grade at } \\
25^{\circ} \mathrm{c}\end{array}$ & $\begin{array}{c}\text { Ductility at } \\
25^{\circ} \mathrm{c}\end{array}$ & $\begin{array}{c}\text { Viscosity } \\
\text { at } 135^{\circ} \mathrm{c}\end{array}$ & Density \\
Unit & - & $(\%)$ & $\left({ }^{\circ} \mathrm{C}\right)$ & $\left({ }^{\circ} \mathrm{C}\right)$ & $(\mathrm{mm} / 10)$ & $(\mathrm{cm})$ & $(\mathrm{mPa} . \mathrm{s})$ & - \\
\hline Value & $64-22$ & 99 & 262 & 54 & 67 & 104 & 349 & 1.03 \\
\hline
\end{tabular}




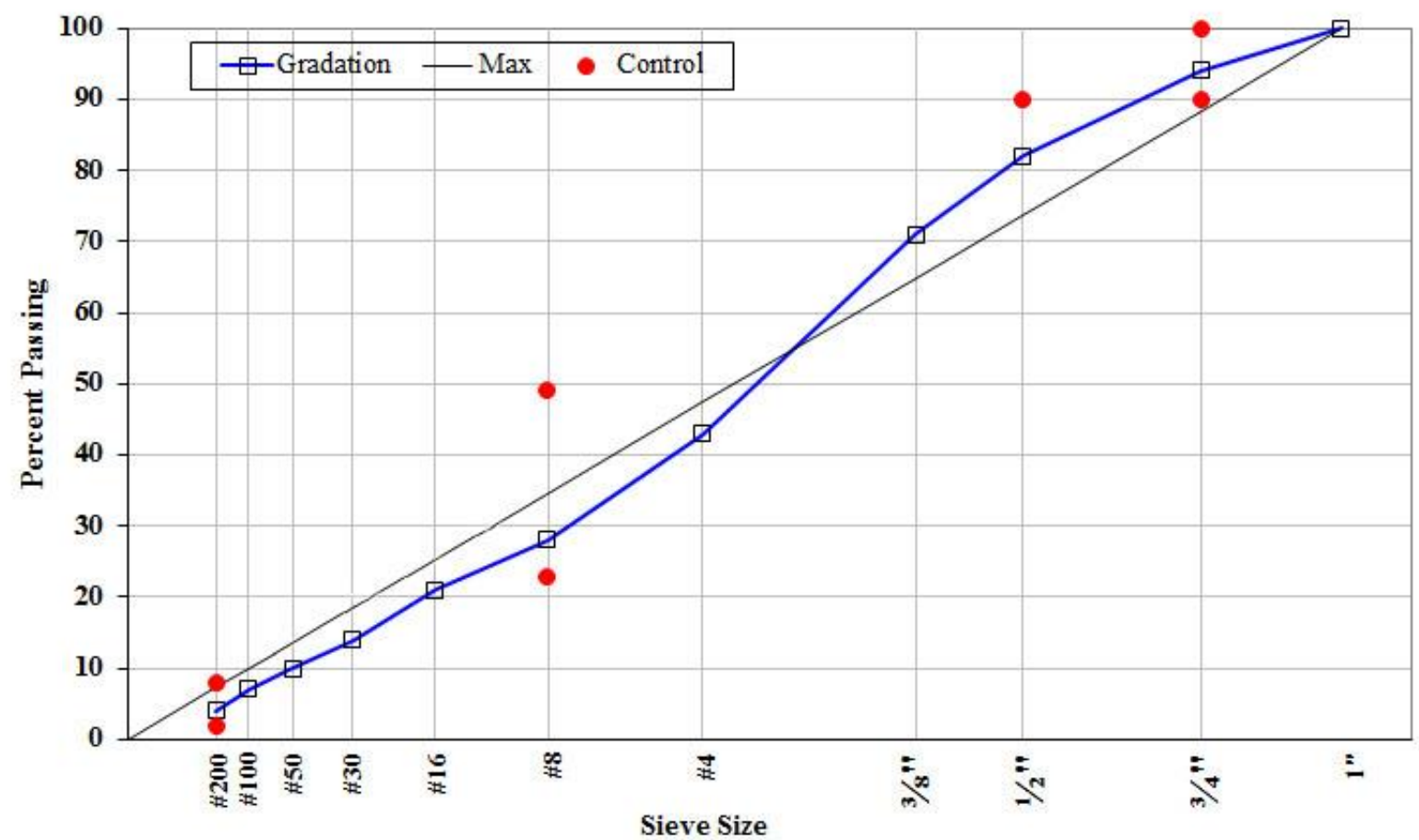

Fig.1. Aggregate Gradation

\subsubsection{Sulfur}

Googas is produced by compounding neat sulfur, plasticizer and some other additives, which

151 is higher than the range of evaporation, melting and freezing points of sulfur. This polymeric

152 sulfur material has been produced in the ZENIT Company (R\&D unit) in granular shape 153 (solid pellet). Produced sulfur pellets can be substituted directly for about half of asphalt in the asphalt concrete and modify the asphalt which was used initially. Using Googas decreases energy consumption via decreasing the temperature needed for mixing and compacting operations. As the asphalt is more expensive than this material, it can decrease the costs of asphalt production and energy consumption [19]. Physical properties of Googas material are shown in Table 2. 


\section{Table 2}

163 Physical properties of Googas.

\begin{tabular}{lc}
\hline Test title & Result \\
\hline Physical shape & Granule \\
Color & Gray \\
Water solubility & Non-soluble \\
Relative specific weight to water & $1.89 \mathrm{gr} / \mathrm{cm} 3$ \\
Average size of pellets & $2 \mathrm{~mm}$ \\
Melting point & Minimum $90^{\circ} \mathrm{C}$ \\
\hline
\end{tabular}

\subsubsection{Nanotechnology zycotherm (NZ)}

Nanotechnology Zycotherm (NZ) is a WMA additive produced by Zydex Company, Gujarat, India. This additive provides two significant benefits for WMA mixtures. It lowers production and compaction temperatures, while simultaneously reducing the moisture susceptibility of asphaltic pavements as an anti-strip agent. The first effect is the result of a reduction in viscosity of asphalt and the second is due to reinforced bond between binder and aggregates. $\mathrm{NZ}$ is an organosilane compound and can form silanols ( $\mathrm{Si}-\mathrm{OH})$ groups. As silanols are so reactive, siloxane bonds $(\mathrm{Si}-\mathrm{O}-\mathrm{Si})$ can be formed between $\mathrm{NZ}$ and inorganic surface-like sand and gravel surfaces which constitute from silanol groups. This additive could be used in different asphaltic mixtures consisting of modified or unmodified asphalt binders. This is very compatible with crumb rubber or polymer modified asphalt binder [20]. Since Googas is a polymeric sulfur product, it could be a suitable additive to modify the studied SEA. Using NZ does not affect binder grading or change any other binder properties. Physical properties of zycotherm additive are shown in Table 3. 
183 Physical properties of zycotherm.

\begin{tabular}{cc}
\hline Properties & Result \\
\hline Form & Liquid \\
Color & Pale yellow \\
Flash point & $>80^{\circ} \mathrm{C}$ \\
Explosion hazard & Not known \\
Density & $1.01 \mathrm{~g} / \mathrm{ml}$ \\
Freezing point & $5^{\circ} \mathrm{C}$ \\
Solubility & Miscible with water \\
PH value & $10 \%$ solution in water neutral or slightly acidic \\
Viscosity & $300 \mathrm{cP}\left(25^{\circ} \mathrm{C}\right)$
\end{tabular}

\subsection{Mixing and HMA sample preparation}

\subsubsection{Mixing $N Z$ in asphalt}

The optimum amount of NZ additive was determined $0.15 \%$ by weight of asphalt.

Viscoelastic characteristics of modified asphalt and ITS parameter of NZ-modified asphalt mixtures were analyzed to achieve this optimum amount, according to the values in Table 4 and Fig. 5, respectively.

The technique which was used to mix NZ in the asphalt binder includes three following steps. before mixing zycotherm in molten asphalt at $150^{\circ} \mathrm{C}$.

2. Zycotherm was added to the center of the vortex at ten drops per minute while maintaining the stirrer speed (According to the dosage of $0.15 \%$ by weight of asphalt, adding $1 \mathrm{ml}$ or $1 \mathrm{~g}$ of zycotherm should take approximately 2 minutes for $660 \mathrm{~g}$ of binder). 
3. The mixing operation performed for 10 minutes to make a completely homogeneous blend.

Within the mixing process, the temperature was set at $150^{\circ} \mathrm{C}$ and kept constant by applying an oil bath heated by a hot plate.

\subsubsection{SEA mixtures preparation}

The optimum binder content (OBC) was determined following Superpave mix design. The OBC for SEA samples was modified by the equation (1). The OBCs were found to be $5.5 \%$ and $4.3 \%$ for conventional and SEA mixtures, respectively. The research team used $35 \%$ Googas by weight of asphalt for constructing sulfur contained samples, which was the optimum amount obtained by doing Indirect Tensile Fatigue (ITF) and Loaded- Wheel Tracking (LWT) tests. Following steps were taken for making SEA mixtures:

1. Used sulfur (Googas) pellets were heated to $60^{\circ} \mathrm{C}$ before adding to the aggregateasphalt mixture.

2. The ASA-modified asphalt was mixed with the hot aggregates at $120^{\circ} \mathrm{C}$.

3. Preheated sulfur pellets were poured into the mixture.

4. The obtained blend was mixed completely at $120^{\circ} \mathrm{C}$ to make all pellets melted and diffused all over the mixture.

Following types of asphaltic samples were constructed and tested:

- Conventional HMA mixtures (CHMA) - mixture made with the neat AC asphalt.

- ASA-modified WMA mixtures (AWMA) - mixture made with ASA-modified asphalt.

- Sulfur- extended WMA mixture (SWMA) - mixture made with sulfur extended asphalt binder. 
- ASA- modified and sulfur extended WMA mixture (ASWMA) - mixture made with ASA- modified binder extended by sulfur.

Triplicate specimens were constructed for every type of asphaltic sample.

\section{Testing program}

\subsection{Scanning electron microscopy (SEM)}

Taking a photo in nano and micro scales is one of the most precise methods to evaluate the efficiency of used mixing procedure. In this study, the SEM method was applied to observe the morphology of sulfur-modified binder as well as investigate the effectiveness of used mixing method to obtain a homogeneous blend.

\subsection{Asphalt binder tests}

To obtain the optimum percentage of $\mathrm{NZ}$ as an antistripping agent additive and evaluate the properties of used binders, empirical rheological tests were performed on neat and NZmodified asphalt binders in different NZ percentages. The research team applied the asphalt tests in accordance with the relevant standards. The penetration degree test is a classic test which determines the hardness of asphalt binder according to the ASTM-D5 standard [21] [22]. Also for determination of softening point degree, the ASTM-D36 was applied [23]. Ductility test was performed to evaluate the cohesion of used asphalt; in this test specimens were stretched at $25^{\circ} \mathrm{C}$ with a constant speed of $5 \mathrm{~cm} / \mathrm{min}$ in accordance with the ASTMD113 [24]. A Brookfield rotational viscometer apparatus was applied to measure the Viscosity of different asphalt binders. During this test, the temperature was set at $135^{\circ} \mathrm{C}$ according to the ASTM-D4402 standard [25]. A number 21 spindle and a specimen size of 8.5 grams were used for this study. 
Different asphaltic samples including CHMA, AWMA, SWMA and ASWMA were

251

252 constructed according to the aforementioned procedures, afterward; Resilient Modulus (RM), ITF, LWT and Indirect Tensile Strength (ITS) tests were conducted on them as follow:

\subsubsection{Resilient modulus test}

In this study, the resilient modulus of asphaltic mixtures was evaluated by the indirect tensile method according to ASTM standard [26] [27]. This test can be used to achieve a good understanding of the elastic properties of studied asphaltic mixture. A Nottingham Asphalt Testing apparatus was applied to determine the resilient modulus of different samples. Dimensions of used cylindrical specimens were $101.6 \mathrm{~mm}$ and $65 \mathrm{~mm}$ in diameter and thickness respectively. The time of an entire loading cycle is $1.0 \mathrm{~s}$ long, which consists of 0.1 $\mathrm{s}$ loading and unloading time and $0.9 \mathrm{~s}$ resting time. When the indirect tensile method is applied for evaluation of elastic properties, the following equation could be utilized to calculate the resilient modulus parameter:

$\mathrm{RM}=\frac{P(v+0.27)}{t * \Delta H}$

Where $\mathrm{RM}=$ resilient modulus $(\mathrm{MPa}) ; \mathrm{t}=$ sample height $(\mathrm{mm}) ; \mathrm{v}=$ Poisson ratio; $\mathrm{P}=$ maximum dynamic load; and $\Delta \mathrm{H}=$ recoverable horizontal deformation (mm).

\subsubsection{Modified Lottman test}

Moisture susceptibility of the specimens was determined by modified lottman test according to AASHTO T283 [28]. Specimens used for Modified Lottman test should be compacted to reach the air voids of $7 \% \pm 1.0$. Dimensions of prepared specimens for this test are $150 \mathrm{~mm}$ and $95 \mathrm{~mm}$ respectively for height and diameter. Six specimens were prepared for every sample including three for unconditioned and three for conditioned mode. Unconditioned 
specimens were not under moisture conditioning before the test, but conditioned specimens were treated by the following stages:

- Immersing in water (up to 55-80\% saturation level).

- Freezing at $-18^{\circ} \mathrm{C}$ for $16 \mathrm{~h}$.

- Placing in a $60^{\circ} \mathrm{C}$ water bath for $24 \mathrm{~h}$.

When this process completed, the ITS for both conditioned and unconditioned specimens was measured at $25^{\circ} \mathrm{C}$. The average ITS was considered as the final values for both conditioned and unconditioned specimens. The TSR parameter is defined as the fraction of conditioned on unconditioned ITS.

\subsubsection{Indirect tensile fatigue (ITF) test}

Research team utilized a Nottingham Asphaltic Mixture Tester to perform the fatigue test. Nottingham tester measures the fatigue life and strains by applying repetitive Indirect Tensile stress to the prepared samples in accordance with relevant ASTM standard for indirect tensile method [26]. The tested specimens were in cylindrical shape and standard dimensions (40 $\mathrm{mm}$ height and $100 \mathrm{~mm}$ diameter). Asphalt mixtures were mixed and compacted in accordance with the superpave mix design standard for construction of specimens [18]. The frequency of loading was $1 \mathrm{~Hz}$ and it continued until the specimen experienced the failure point. The failure point was also defined as $12.7 \mathrm{~mm}$ final vertical deformation or occurring rupture in the loaded specimen. Controlled stress mode was chosen as the condition of loading for the fatigue test in this study. In the controlled stress mode, the applied stress should be kept constant to increase the strain of loaded specimen. 
In this study 5,15 and $25^{\circ} \mathrm{C}$ were chosen as the temperature of test to simulate the fatigue phenomenon at the low-temperature condition. Two stresses of $100 \mathrm{kPa}$ and $300 \mathrm{kPa}$ were selected as the constant values of applied load. A common equation (Wohler's fatigue equation) is usually used to show the relationship between the number of cycles to failure and tensile strain. Such an equation could be obtained if the linear diagram of the relationship between the "loading number to the failure point" (fatigue life) and the "applied strain" be drawn on a logarithmic scale using a regression analysis [29]. Developed fatigue equations would be in the form of Wohler's fatigue equation (Eq. (3)):

$\mathrm{N}=\mathrm{a}\left[\frac{1}{\varepsilon_{\mathrm{t}}}\right]^{\mathrm{b}}$

Where " $\mathrm{N}$ " = loading number to the failure point; $\varepsilon_{\mathrm{t}}=$ measured strain; "a" and "b" = coefficients effected by asphalt mixture properties.

\subsubsection{Loaded- Wheel tracking (LWT) test}

The LWT test has been applied for asphaltic mixtures accelerated performance testing in terms of its rutting resistance according to AASHTO T324 [30]. A Hamburg wheel rut tester was used to measure rut depth of different sample influenced by repetitive loading condition in which specimens with a $30-30-6 \mathrm{~cm}$ dimensions were used to simulate rutting phenomenon of real loaded pavement. In this study, the wheel track testing was carried out by applying $703-\mathrm{N}$ steel wheel on the submerged specimen at temperature $50{ }^{\circ} \mathrm{C}$. The wheeltracker apparatus was programmed to finish rolling after 20,000 cycles or when the maximum displacement recorded by LVDT was $20 \mathrm{~mm}$. The maximum allowable permanent deformation was determined to be $6 \mathrm{~mm}$ after 20,000 passes at $50^{\circ} \mathrm{C}$. This value is required to consider a sample resistant against rutting phenomenon. 


\section{Results and discussions}

322

323

324

\subsection{SEM analysis results}

One of the most reliable methods to evaluate mixing operation-effectiveness is to take photos in micro and nano scales by SEM microscopes [31]. Morphology of neat asphalt and Googasmodified asphalt is illustrated in Fig. 2. Photos were taken at a voltage of $5 \mathrm{KV}$ with 30060000 magnification scale. As illustrated in Table 2, the average size of unmixed Googas pellets was about $2 \mathrm{~mm}$. To use the full potential of Googas as asphalt extender, it is necessary to dissolve it in asphalt and make a homogeneous blend as much as possible. As shown in Fig. 2-D, a major part of Googas pellets almost dissolved into the asphalt bulk and made it more viscous, but other part was not fully dissolved at high mixing temperature and, therefore, became crystallized at lower temperatures which can be seen in Fig. 2-C. In these two figures white parts are sulfur and black parts are asphalt. In Fig. 2-D dissolved sulfur can be distinguished because of high focus of picture as could be understood from the scales. In SEA mixtures, sulfur gets cooled and crystallized around the coarse aggregates and makes the mixture stiffer than before. Extra stiffness caused by dissolved and crystallized sulfur improves rutting performance of SEA [7].

Increased viscosity normally raises the necessary temperature for mixing and compaction operations, while Googas which is a polymeric sulfur product, reduces these temperatures beside increment of viscosity that could be so favorable. This mechanism occurs due to the improved properties of Googas product compared to the neat sulfur as a result of applied treatments. 


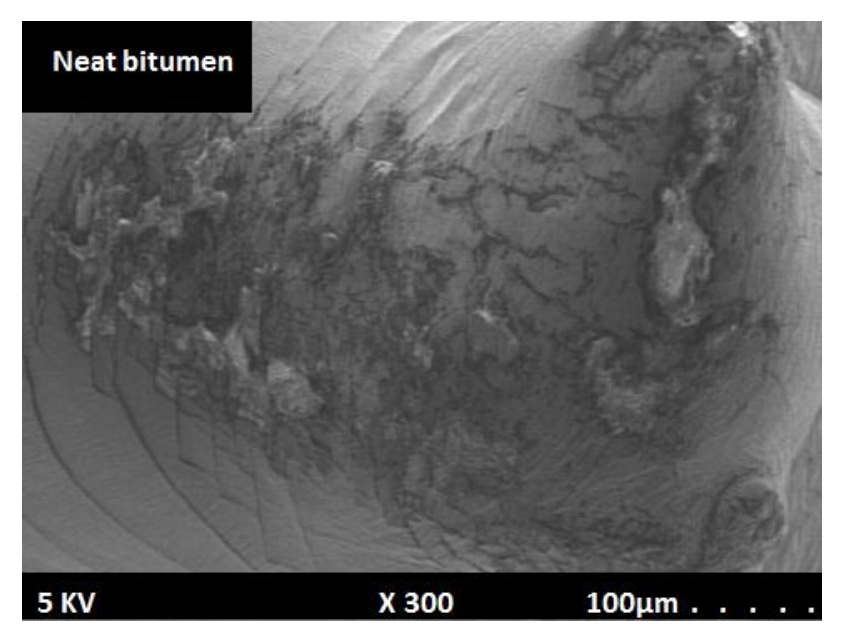

A

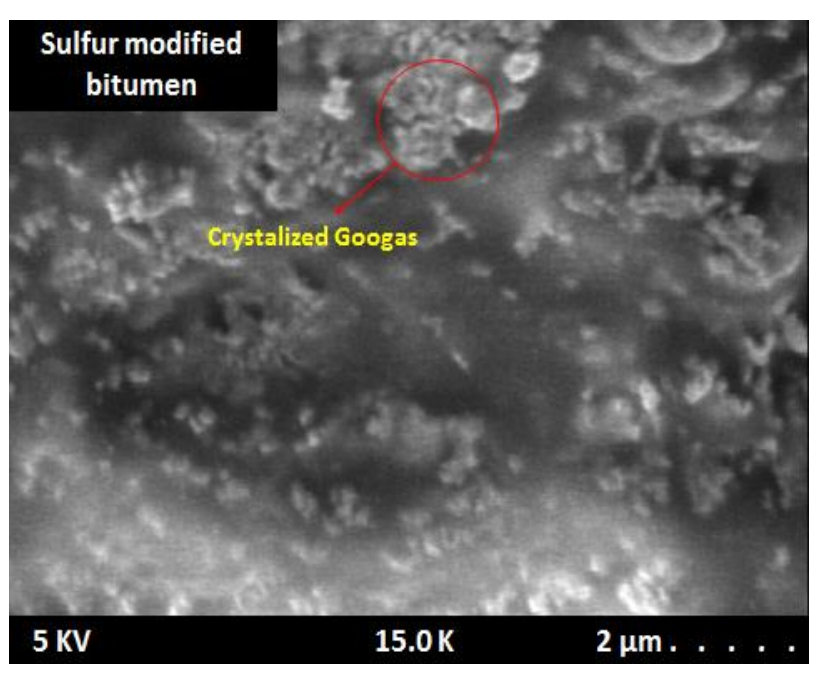

$\mathrm{C}$

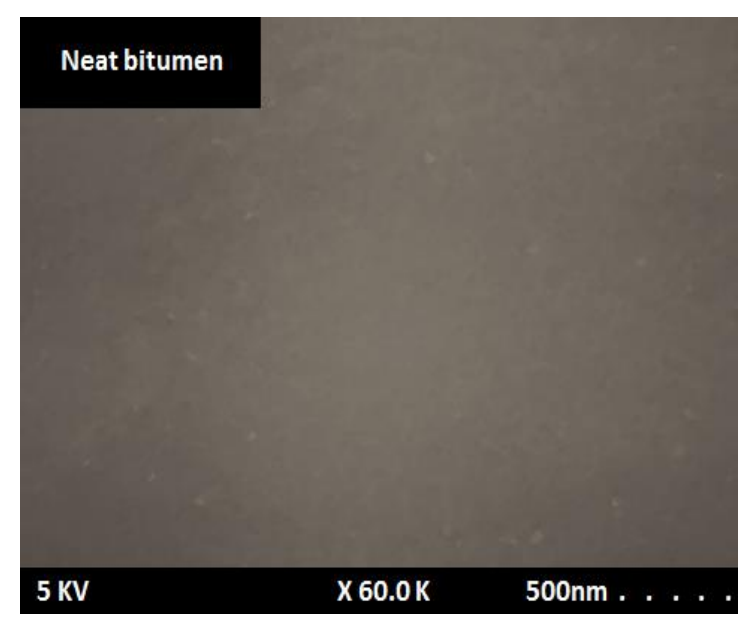

B

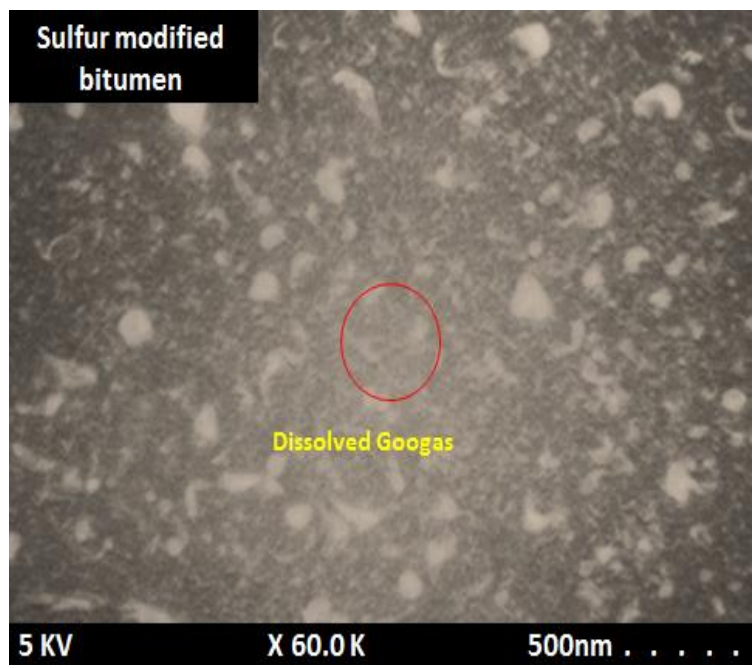

$\mathrm{D}$

Fig. 2. SEM images of sulfur - modified/unmodified asphalt, (A) Neat asphalt - 100 $\mu \mathrm{m}$; (B)

Neat asphalt - 500nm; (C) sulfur-modified asphalt binder - $2 \mu \mathrm{m}$; (D) sulfur-modified asphalt

$$
\text { binder }-500 \mathrm{~nm} \text {. }
$$

\subsection{Asphalt binder test results}

347 To obtain the optimum percentage of NZ as an antistripping agent additive and evaluate the

348 properties of the used binders, empirical and rheological tests were performed on the neat

349 asphalt, the NZ modified asphalt in different NZ percentages as well as sulfur and/or NZ modified asphalts in optimum percentages. As shown in Table 4, the more the NZ content, the more penetration degree, and consequently, the less softening point observed. These 
changes were due to the lower viscosity of NZ- modified asphalt compared to the neat asphalt. As shown in Table 4, NZ- modified asphalt has better ductility than the neat one.

354 This improvement could be attributed to the formation of bonds between chemical 355 compositions of AC with NZ particles. The viscosity data of different samples including neat 356 and modified asphalt at a temperature of $135{ }^{\circ} \mathrm{C}$ was collected by standard Rotational

357 Viscosity (RV) test. As it is shown in Table 4, all samples had a viscosity value less than the 358 SHRP limit of $3000 \mathrm{MPa} . \mathrm{s}$ at $135^{\circ} \mathrm{C}$. Addition of $\mathrm{NZ}$ to asphalt should not affect the binder grading negatively, so $0.15 \% \mathrm{NZ}$ was chosen as the optimum percentage of ASA additive.

360 According to the rheological and empirical tests' results, adding sulfur made asphalt more

361 brittle by increasing RV and softening point as well as decreasing ductility and penetration degree, while using ASA restores these properties to the neat asphalt condition to a high extent.

\section{Table 4}

366 Basic properties of NZ and/or Sulfur modified asphalt.

\begin{tabular}{|c|c|c|c|c|c|}
\hline property & PG & $\begin{array}{c}\text { Rotational viscosity } \\
\text { at } \\
135^{\circ} \mathrm{C} \text { (mPa.s) }\end{array}$ & $\begin{array}{l}\text { Ductility at } \\
25^{\circ} \mathrm{C} \text { at }\end{array}$ & $\begin{array}{l}\text { Penetration at } \\
225^{\circ} \mathrm{C}\end{array}$ & $\begin{array}{l}\text { Softening } \\
\text { Point }\left({ }^{\circ} \mathrm{C}\right)\end{array}$ \\
\hline $\begin{array}{c}\text { Standard } \\
\text { Unit }\end{array}$ & $\begin{array}{c}\text { ASTM D } 6373 \\
- \\
\end{array}$ & $\begin{array}{c}\text { ASTM-D4402 } \\
(\mathrm{mpa})\end{array}$ & $\begin{array}{l}\text { ASTM D113 } \\
(\mathrm{cm})\end{array}$ & $\begin{array}{l}\text { ASTM-D5 } \\
(\mathrm{mm} * 0.1)\end{array}$ & $\begin{array}{c}\text { ASTM-D36 } \\
\left({ }^{\circ} \mathrm{C}\right)\end{array}$ \\
\hline Neat asphalt & $64-22$ & 349 & 104 & 67 & 54 \\
\hline Modified asphalt with $0.1 \% \mathrm{NZ}$ & $64-22$ & 336 & 110 & 69 & 51 \\
\hline Modified asphalt with $0.15 \% \mathrm{NZ}$ & $64-28$ & 329 & 114 & 70 & 49 \\
\hline Modified asphalt with $0.20 \% \mathrm{NZ}$ & $58-28$ & 325 & 120 & 71.3 & 48 \\
\hline ASA- modified asphalt (15\%NZ) & $64-28$ & 329 & 114 & 70 & 49 \\
\hline $\begin{array}{l}\text { Sulfur- modified asphalt (35\% } \\
\text { Googas) }\end{array}$ & $70-10$ & 412 & 92 & 58 & 52 \\
\hline $\begin{array}{l}\text { ASA and sulfur- modified asphalt } \\
\text { (15\%NZ and 35\% Googas) }\end{array}$ & $70-22$ & 371 & 101 & 60 & 46 \\
\hline
\end{tabular}


In general, a pavement which has high resilient modulus is expected to resist appropriately against permanent deformation [32]. Results of resilient modulus test at different temperatures for CHMA, AWMA, SWMA and ASWMA mixtures have been illustrated in Fig. 3. As seen, the stiffness of studied mixes reduced by increasing the temperature. According to the Fig 3, the resilient modulus of asphaltic samples amplified by about $30 \%$ and $100 \%$ respectively for SEAs (SWMA and ASWMA) and sulfur- unmodified samples (CHMA and AWMA) by lowering the temperature from $25^{\circ} \mathrm{C}$ to $5^{\circ} \mathrm{C}$. At any constant temperature, the highest stiffness quantity was achieved for SWMA follow by ASWMA, CHMA, and AWMA mixtures. As depicted in Fig 3, in comparison of CHMA with AWMA, the rate of resilient modulus reduction due to the addition of ASA is more considerable at lower temperatures. On the other hand, in comparison of CHMA with SWMA, the rate of resilient modulus improvement due to the addition of Googas was more considerable at higher temperatures. The reduction of the binder viscosity around the aggregate particles at high temperatures was the main reason for this difference. Dissolved sulfur in the asphalt made it stiffer, and more viscose in different temperatures; also, crystallized sulfur around the aggregates made a more powerful bond between sulfur- modified binder and aggregates. Therefore, the binder film around the aggregates was more stable for SEAs samples compared to the other samples especially at higher temperatures [33]. According to the viscosity test data, increasing NZ content had decreased binder viscosity that led reduction of binder film around aggregates; therefore, as illustrated in Fig.3, AWMA has lower stiffness modulus in comparison with CHMA at different temperatures. As obviously portrayed in Fig. 3, the highest resilient modulus improvement rate of SWMA and ASWMA occurred at higher temperatures. Using ASA reduced SEA mixture's resilient modulus slightly, but this deterioration was negligible especially at higher temperatures. 


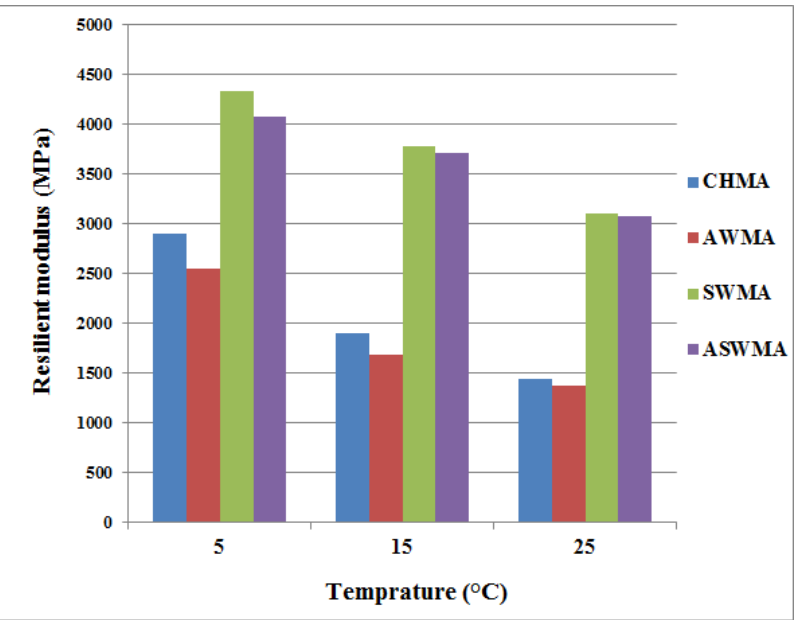

Fig. 3.Comparison of resilient modulus values at 5,15 and $25^{\circ} \mathrm{C}$.

\subsubsection{Moisture resistance performance}

400

The results of the ITS test are summarized graphically in Fig.4 and Fig. 5. Diagrams in Fig. 4 show a reduction (approximately 19\%) in the splitting tensile strength of the ASWMA versus the AWMA in a conditioned situation as a consequence of adding Googas. The same parameter increased $41 \%$ for AWMA in comparison with CHMA due to applying ASAmodified asphalt. By considering $80 \%$ as the minimum acceptable TSR value, CHMA and SWMA samples showed inadequate moisture resistance (respectively $77 \%$ and 68\%).Fig. 5 shows that both AWMA and ASWMA had an acceptable resistance to moisture damage, with TSR value above 0.8 for each mixture ( 0.90 for AWMA and 0.85 for ASWMA). Therefore, AWMA and ASWMA samples which were modified by NZ as an anti- stripping agent 409 showed improved moisture susceptibility compared to CHMA and SWMA samples. 410 Comprehensively, these comparisons demonstrated that Googas lowers indirect tensile strength (ITS) and tensile strength ratio (TSR), but ASA improves them significantly. 


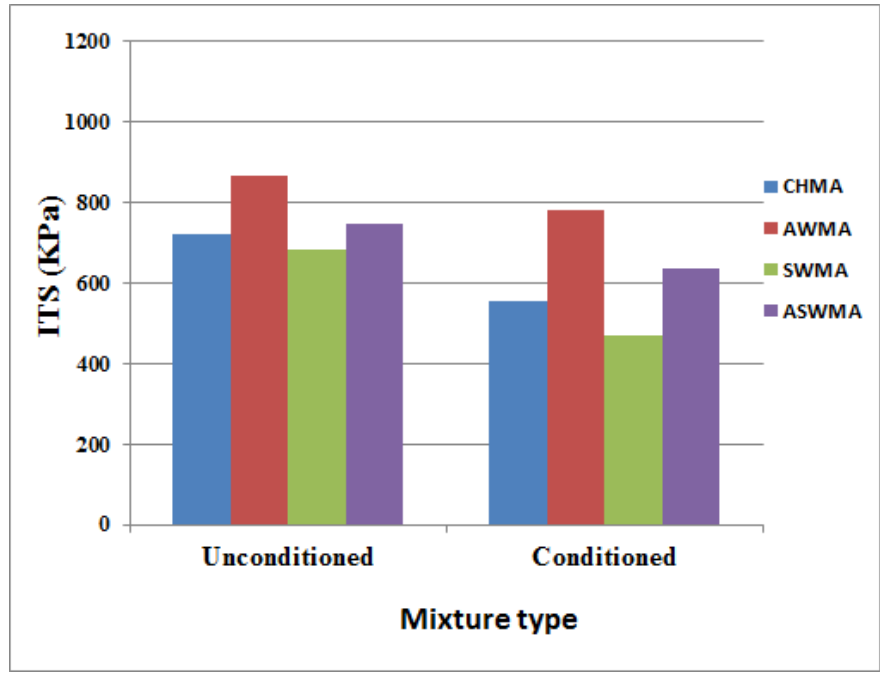

Fig. 4. The indirect tensile strength of unconditioned and conditioned specimens.

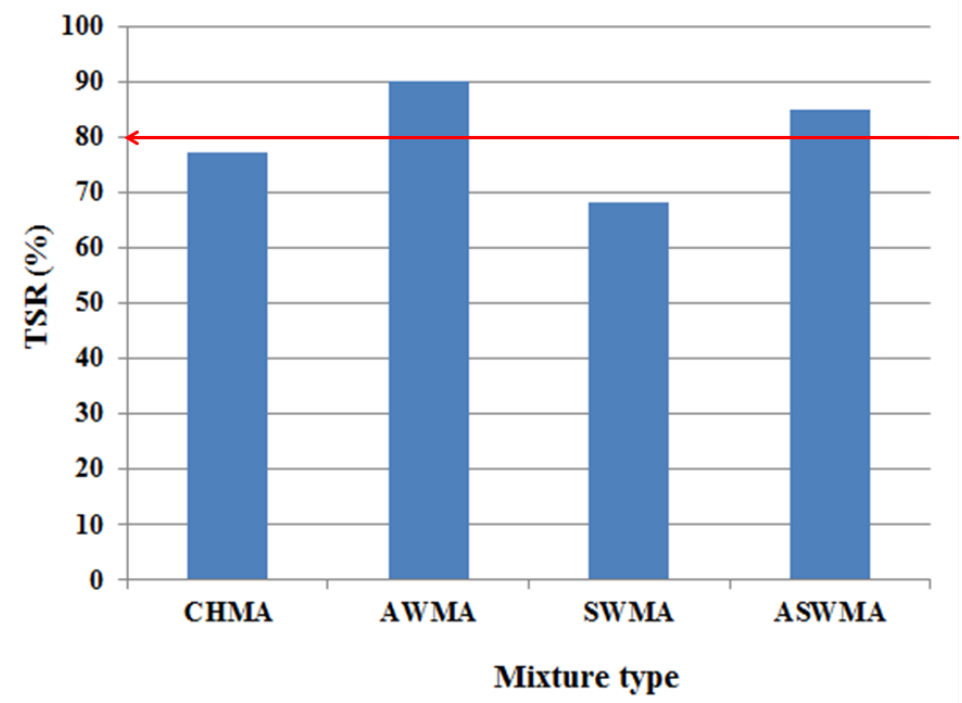

Fig. 5.TSR values vs. mixture type.

\subsubsection{Fatigue performance}

418 As results of performed fatigue tests, the correlations between the number of cycles and the 419 strain level applied to the specimens at 5, 25 and $40{ }^{\circ} \mathrm{C}$ under 100 and $300 \mathrm{KPa}$ stresses are 420 illustrated in Fig. 6. Results indicated the beneficial effects of NZ and deteriorative effect of 421 Googas on the fatigue life of studied mixtures. Also, reduction in the mixtures' temperature 422 led to the increment of the fatigue life at aforementioned stress levels. Fig. 6 compares the 423 fatigue curves of four specimens including CHMA, AWMA, SWMA and ASWMA. Between 

SWMA. As mentioned earlier, the crystallized part of sulfur particles and dissolved part in the asphalt during the mixing process, decreases the binder's ductility and flexibility; thus, a

427 lower fatigue resistance and flexibility were observed in the SEA mixtures. However, 428 considering stiffness properties exhibited in the previous section, the improved resilient 429 modulus of SEA mixtures will decrease strain magnitude applied to the pavement structure. 430 This phenomenon could have a beneficial effect on the SEAs fatigue behavior in real 431 condition, in which the pavement structure bears stress-controlled vehicular loading instead 432 of strain-controlled loading, as was chosen as loading condition in the laboratory [7].

433 AWMA had the longest fatigue life which could be justified by the lower stiffness and 434 viscosity of this sample as well as a developed bond between asphalt and aggregates as a result of ASA- modification. On the other hand, as demonstrated by ITS test in the previous section, using NZ can lead to high tensile strength in NZ- modified asphalt mixtures.

437 Improved tensile strength leads to the postponing of micro-cracks generation and propagation 438 which subsequently postpones fatigue failure. As illustrated in Fig.6, the ASWMA had 439 slightly flatter slope compared to the SWMA, which demonstrates that NZ-modified SEA possesses higher fatigue life at a greater strain. Coefficients of fatigue equations are shown in the table. 5 . 


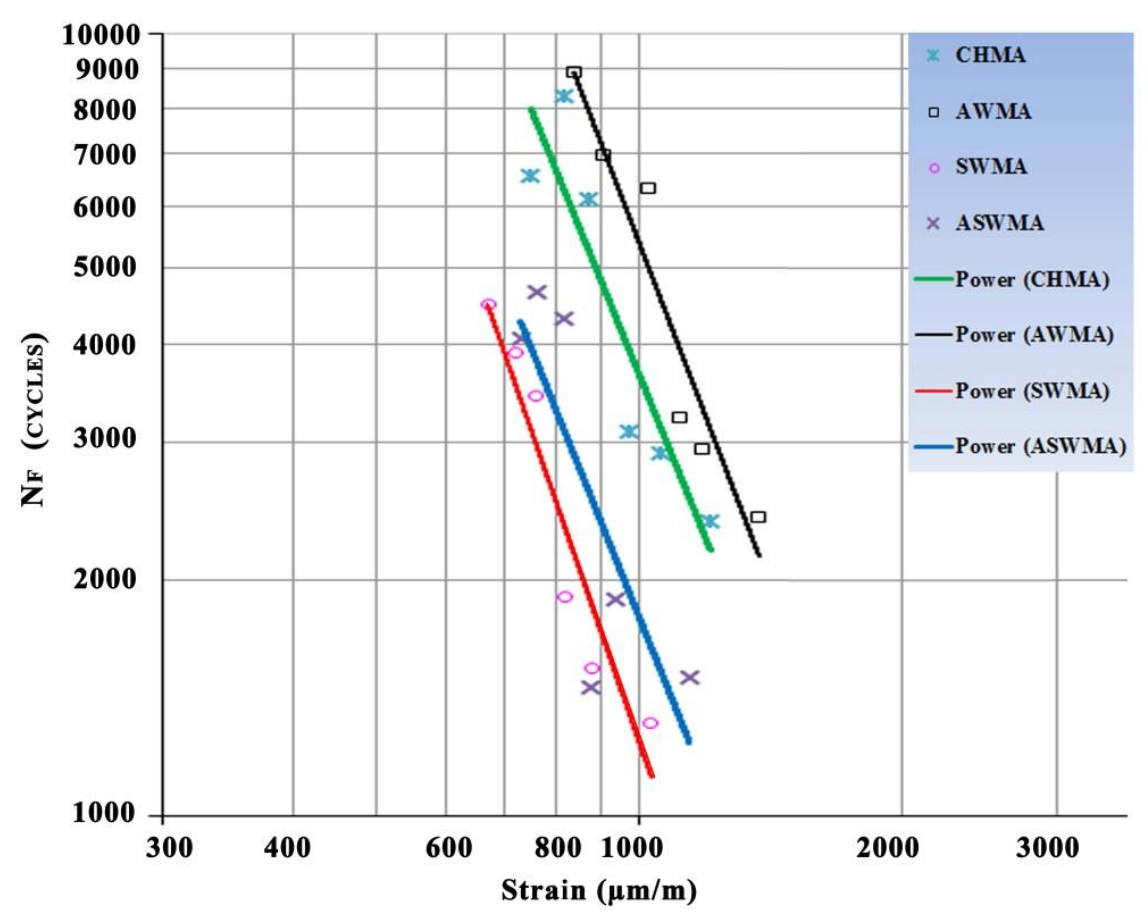

442

443

444

445

446

449

450

451

452

453

Fig. 6.ITF test results.

\section{Table 5}

Coefficients of the fatigue equations.

\begin{tabular}{cccc}
\hline \multirow{2}{*}{ Asphalt mixture } & \multicolumn{2}{c}{ Coefficient of the fatigue equations } & $R^{2}$ \\
\cline { 2 - 3 } & $\mathrm{a}$ & $\mathrm{b}$ & \\
\hline CHMA & $6 \mathrm{E}+11$ & -2.74 & 0.841 \\
AWMA & $3 \mathrm{E}+12$ & -2.91 & 0.918 \\
SWMA & $6 \mathrm{E}+12$ & -3.22 & 0.903 \\
ASWMA & $4 \mathrm{E}+11$ & -2.78 & 0.764 \\
\hline
\end{tabular}

\subsubsection{Rutting performance}

The rutting resistance of the four evaluated samples is illustrated in Fig. 7. As it was mentioned previously, maximum permissible rut depth of $6 \mathrm{~mm}$ after 20,000 cycles at $50^{\circ} \mathrm{C}$ is acceptable. As seen in Fig. 7, the results of the Hamburg testing showed that both the ASWMA and SWMA had met the desirable deformation resistance considering the stated criterion. These two samples almost showed a similar rate of increase and ultimate resistance 
which demonstrate that adding NZ as the anti-stripping agent does not have a considerable

455

456

457

458

459

460

461

462

463

464

465

466

467

468

469

470 effect on the rutting resistance of asphaltic mixtures. On the other hand, sample AWMA showed the weakest resistance against rutting at 20,000 cycles, followed by CHMA, as shown in Fig. 7. Both of these samples were not modified with sulfur, therefore had less stiffness than SEA samples and consequentlywere weaker against rutting phenomenon.

As shown in Fig. 7, specimens ASWMA and SWMA showed a rutting value at 20,000 cycles that were less than $6.0 \mathrm{~mm}$; therefore, SEA samples had sufficient rutting resistance, unlike two other samples.

- (Log. (SWMA - (Log. (ASWMA

- (Log. (CHMA - (Log. (AWMA

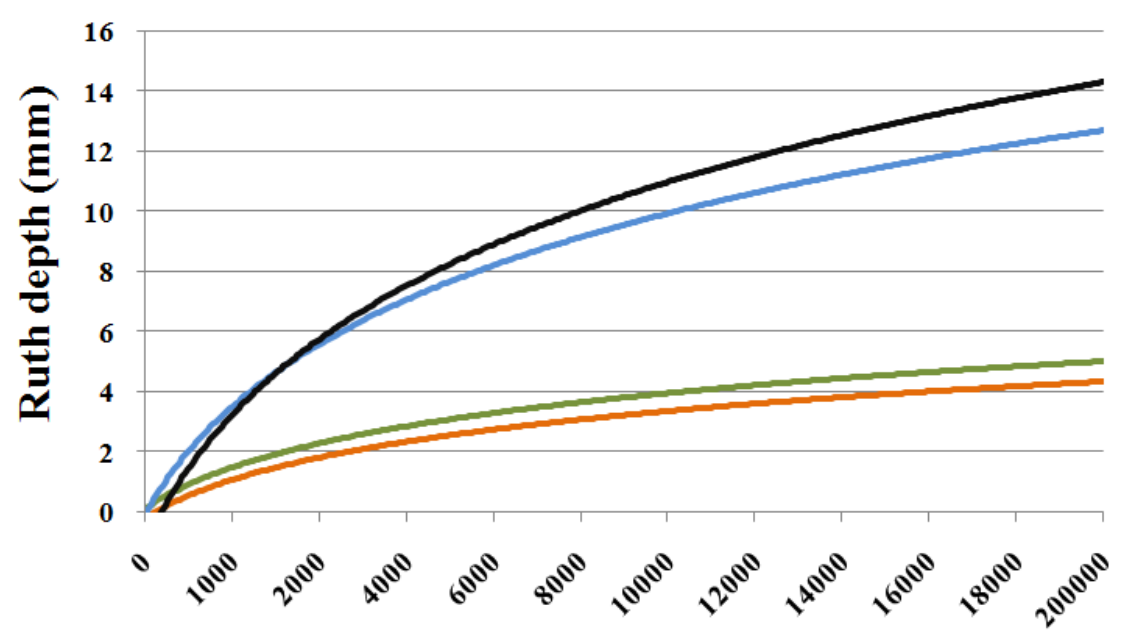

Number of passes

Fig. 7. Wheel track test results at $50{ }^{\circ} \mathrm{C}$.

\section{Conclusion}

This study evaluated the effectiveness of using a new generation of modified- sulfur and ASA additives in the production of warm-mix asphalt. In this study, the moisture susceptibility and some of the mechanical properties of conventional HMA and ASA and/or sulfur- modified mixtures were evaluated and compared. The modification of asphalt mixture with Googas (treated sulfur) and the use of nanotechnology Zycotherm as the anti-stripping agent resulted 
in an efficient additives combination which leads benefiting improved properties of SEAs while omitting or attenuating its defects. In addition:

- As it was shown in SEM pictures, mixing procedure was a successful technique to mix Googas in asphalt mixtures and make an almost homogeneous Googas-asphalt matrix. Some parts were dissolved to an acceptable degree and some crystallized at micro and nano scales.

- Extending a portion of asphalt by Googas led to a mixture with a higher resilient modulus which was more resistant to permanent deformation. This increase was about $50 \%$ and $100 \%$ at low and high temperatures respectively. Using ASA reduced SEA mixture's resilient modulus slightly, but this deterioration was negligible especially at higher temperatures (lower than 4\%).

- Obtained results by Lottman test demonstrated that Googas reduced indirect tensile strength (ITS) about $8 \%$ and tensile strength ratio (TSR) about $12 \%$, but on the other hand, ASA improved them significantly by about $42 \%$ and $28 \%$ respectively. Therefore, moisture susceptibility of ASA-modified SEA (ASWMA) was significantly improved compared with unmodified SEA. As a result, modification of SEA by the use of ASA (Zycotherm) was a successful method to reduce moisture susceptibility of SEA mixture.

- SEA mixtures showed the least fatigue life. However, the greater modulus of SEA mixtures reduced the magnitude of strain induced in the sample (about $20 \%$ ). Furthermore, antistripping agent increased fatigue life (about $25 \%$ ) by developing adhesion between asphalt and aggregates.

- As a result of higher stiffness, the rut depth of SEA mixtures decreased by about $300 \%$ at the last cycle of the loading process in comparison with conventional asphalt 
mixture. Using ASA attenuated this improvement slightly, but the reduction was negligible (about 25\%).

498

499

500

501

502

503

504

505

506

507

508

509

510

511

512

513

514

515

516

517

518

519

Overall, conclusions of this research indicate that mechanical characteristics of asphaltic mixture improve by sulfur modification, essentially about rutting phenomenon. On the other hand, nanotechnology Zycotherm as an anti-stripping agent could improve adhesion between aggregates and sulfur- extended asphalt, therefore, improve the deteriorated parameters caused by sulfur modification, such as moisture susceptibility and fatigue resistance.

\section{Reference}

[1] Golestani, B., Nam, B. H., Nejad, F. M., \& Fallah, S. (2015). Nanoclay application to asphalt concrete: Characterization of polymer and linear nanocomposite-modified asphalt binder and mixture. Construction and Building Materials, 91, 32-38.

[2] Arabani, M., \& Faramarzi, M. (2015). Characterization of CNTs-modified HMA's mechanical properties. Construction and Building Materials, 83, 207-215.

[3] Cocurullo, A., Grenfell, J., Yusoff, N. I. M., \& Airey, G. (2012, January). Effect of Moisture Conditioning on Fatigue Properties of Sulphur Modified Asphalt Mixtures. In 7th RILEM International Conference on Cracking in Pavements (pp. 793-803). Springer Netherlands.

[4] Kennedy, T. W., Haas, R., Smith, P., Kennepohl, G. A., and Hignell, E. T. (1977). "Engineering evaluation of sulphur-asphalt mixtures." Transportation Research Record 659, Transportation Research Record, Washington, DC, 12-17.

[5] Deme, I., and Kennedy, B. (2004). "Use of sulfur in asphalt pavements.” SURF 2004: 5th Int. Symp. on Pavement Surface Characteristics, Roads and Airfields, Toronto. 
[6] Taylor, A., Tran, N., May, R., Timm, D., Robbins, M., and Powell, B. (2010). "Laboratory evaluation of sulfur-modified warm mix.” J. Assoc. Asphalt Paving Technol., $79,403-442$.

[7]Cooper III, S. B., Mohammad, L. N., \& Elseifi, M. A. (2011). Laboratory performance characteristics of sulfur-modified warm-mix asphalt. Journal of Materials in Civil Engineering, 23(9), 1338-1345.

[8] DiVito, J. A., \& Morris, G. R. (1982). Silane pretreatment of mineral aggregate to prevent stripping in flexible pavements , Transportation Research. Record, No. 843, 104-111.

[9] Arabani, M., Roshani, H., \& Hamedi, G. H. (2011). Estimating moisture sensitivity of warm mix asphalt modified with zycosoil as an antistrip agent using surface free energy method. Journal of Materials in Civil Engineering,24(7), 889-897.

[10] Bencowitz, I., \& Boe, E. S. (1938). Effect of Sulphur upon some of the Properties of Asphalts. In Proc. ASTM (Vol. 38, No. Part II, p. 539).

[11] Kennepohl, G. J. A., Logan, A., \& Bean, D. C. (1975, February). Conventional Paving Mixes with Sulphur-Asphalt Binders. In Proceedings of the Association of Asphalt Paving Technologists (Vol. 44, pp. 485-518).

[12] Beatty, T. L., Dunn, K., Harrigan, E. T., Stuart, K., \& Weber, H. (1987). Field Evaluation of Sulfur-Extended Asphalt Pavements. Transportation Research Record, 1115 , Asphalt Materials and Mixtures, p. 161-170.

[13] Strickland, D., Colange, J., Martin, M., \& Deme, I. (2009). Performance properties of sulphur extended asphalt mixtures with modified sulphur pellets.Proceedings of the International Society for Asphalt Pavements.

[14] Timm, D., Tran, N., Taylor, A., Robbins, M., and Powell, B. (2009). "Evaluation of mixture performance and structural capacity of pavements using Shell Thiopave, Phase I: Mix design, laboratory performance evaluation and structural pavement analysis and design." 
545 NCAT Rep. 09-05, National Center for Asphalt Technology, Auburn, AL.

546 [15] Kentucky Product Evaluation List. (2010). "Shell Thiopave.” 〈http://www .ktc.uky.edu〉

547 (June 2010).

548 [16] Strickland, D., Colange, J., Shaw, P., \& Pugh, N. (2008). A Study of the Low-

549 Temperature Properties of Sulphur Extended Asphalt Mixtures. In Canadian Technical 550 Asphalt Association.

551 [17] Cooper III, S. B., Elseifi, M., Mohammad, L. N., \& Hassan, M. (2012). Performance and 552 Cost-Effectiveness of Sustainable Technologies in Flexible Pavements Using the 553 Mechanistic-Empirical Pavement Design Guide. Journal of Materials in Civil 554 Engineering, 24(2), 239-247.

555 [18] Asphalt Institute SP-1 "Superpave Performance Graded Asphalt” (1996).

556 [19] Shafabakhsh, G. H., Faramarzi, M., \& Sadeghnejad, M. (2015). Use of Surface Free 557 Energy method to evaluate the moisture susceptibility of sulfur extended asphalts modified 558 with antistripping agents. Construction and Building Materials, 98, 456-464.

559 [20] Zhang, F., \& Hu, C. (2013). The research for SBS and SBR compound modified asphalts 560 with polyphosphoric acid and sulfur. Construction and Building Materials, 43, 461-468.

561 [21] ASTM Standard D5/D5M. (2013). Standard Test Method for Penetration of Bituminous Materials, ASTM International, West Conshohocken.

[22] Galooyak, S. S., Dabir, B., Nazarbeygi, A. E., \& Moeini, A. (2010). Rheological properties and storage stability of asphalt/SBS/montmorillonite composites. Construction and Building Materials, 24(3), 300-307.

[23] ASTM Standard D36 / D36M. (2009). Standard Test Method for Softening Point of Asphalt (Ring-and-Ball Apparatus). ASTM International, West Conshohocken. [24] ASTM D 113-99. (2002). Standard Test Method for ductility Test, ASTM International, 569 West Conshohocken. 
570

571

572

573

574

575

576

577

578

579

580

581

582

583

584

585

586

587

588

589

590

[25] ASTM-D4402. Standard test method for viscosity determination of asphalt at elevated temperatures using a rotational viscometer. American Society for Testing and Materials; 2006.

[26] ASTM D4123. (2000). Standard Test Method for Indirect Tension Test for Resilient Modulus of Bituminous Mixtures Annual book of ASTM Standards. , ASTM International, West Conshohocken.

[27] Yang, J., \& Yin, C. (2009). Laboratory Study of Porous Asphalt Mixture Made with Rubber Asphalt. Material, Design, Construction, Maintenance, and Testing of Pavement (Geotechnical special publication NO. 195). American Society of Civil Engineers (ASCE), Changsha, 22-31.

[28] AASHTO, T. 283. (2003). "Standard method of test for resistance of compacted asphalt mixtures to moisture-induced damage". American Association of State and Highway Transportation Officials, Washington, DC.

[29] Nejad, F. M., Aflaki, E., \& Mohammadi, M. A. (2010). Fatigue behavior of SMA and HMA mixtures. Construction and Building Materials, 24(7), 1158-1165.

[30] AASHTO, T. 324 (2011). “. Standard Method of Test for Hamburg Wheel-Track Testing of Compacted Hot-Mix Asphalt (HMA)," American Association of State and Highway Transportation Officials, Washington, DC.

[31] Faramarzi, M., Arabani, M., Haghi, A. K., \& Mottaghitalab, V. (2015). Carbon Nanotubes-modified Asphalt Binder: Preparation and Characterization. International Journal of Pavement Research and Technology, 8(1):29-37. 
591 [32] An, J., Golestani, B., Nam, B. H., \& Lee, J. L. (2015, June). Sustainable utilization of

592 MSWI bottom ash as road construction materials, part I: Physical and mechanical evaluation.

593 In Airfield and Highway Pavements 2015.

594 [33] Polacco, G., Stastna, J., Vlachovicova, Z., Biondi, D., \& Zanzotto, L. (2004). Temporary

595 networks in polymer modified asphalts. Polymer Engineering \& Science, 44(12), 2185-2193.

596 